\title{
Erratum to: Diagnostic challenge of atypical colorectal metastasis to the renal pelvis
}

\author{
Bastian Keck • Tilman T. Rau • Frens S. Krause • \\ Bernhard Walter • Peter J. Goebell • Arndt Hartmann • \\ Bernd Wullich
}

Published online: 17 August 2010

(C) Springer-Verlag 2010

\section{Erratum to: Int J Colorectal Dis}

\section{DOI 10.1007/s00384-010-0987-5}

The original version of this article unfortunately contained a mistake. The authors' names are incorrectly presented. The correct presentation is: Bastian Keck, Tilman Rau, Frens Steffen Krause, Bernhard Walter, Peter J. Goebell, Arndt Hartmann, Bernd Wullich.

The online version of the original article can be found at http://dx. doi.org/10.1007/s00384-010-0987-5.

B. Keck $(\varangle) \cdot$ F. S. Krause $\cdot$ B. Walter $\cdot$ P. J. Goebell • B. Wullich Department of Urology, University Hospital of Erlangen,

Krankenhausstr 12,

91054 Erlangen, Germany

e-mail: Bastian.Keck@uk-erlangen.de

T. T. Rau $\cdot$ A. Hartmann

Department of Pathology, University Hospital of Erlangen,

Erlangen, Germany 